\title{
Stoichiometric measurement of the acrosin content of a guinea-pig spermatozoon
}

\author{
D. P. L. Green \\ Department of Pharmacology, University of Otago Medical School, P.O. Box 913, Dunedin, \\ New Zealand
}

\begin{abstract}
Summary. Guinea-pig spermatozoa were induced to undergo an acrosome reaction with the ionophore A23187. A time course for the activation of protease activity was established. Acid treatment of fully activated spermatozoa at $\mathrm{pH} 2.35$ for $30 \mathrm{~min}$ exposed additional activity. This was attributed to the acid dissociation of a protein inhibitor from acrosin. The acrosin content of fully activated and acid-dissociated sperm extracts was measured using a sensitive active-site titrant for serine proteases. The number of acrosin molecules per spermatozoon, calculated on the basis of the sperm count, was approximately $2 \times 10^{6}$, of which half were available without dissociation of the inhibitor.
\end{abstract}

Keywords: guinea-pig; spermatozoa; acrosin; active-site titration

\section{Introduction}

Mammalian spermatozoa penetrate the zona pellucida during the course of fertilization, forming a penetration slit as they do so. The various thrusting movements which spermatozoa execute play an essential role in penetration, although it is still not clear whether the penetration slit is formed by mechanical forces alone (Green \& Purves, 1984; Green, 1987, 1988; Baltz et al., 1988; Drobnis et al., 1988). Indeed, it has long been the view, based on speculation about the function of the acrosome, that the penetration slit is formed by a zona lysin which is secreted or exposed by the acrosome during the acrosome reaction. There are currently two proposals for the manner in which such a zona lysin might be deployed. The longstanding view is that it remains attached to the sperm surface after the acrosome reaction (Austin \& Bishop, 1958), so that any digestion of the zona pellucida which takes place is through direct contact between the zona pellucida and the sperm surface. A more recent proposal is that the zona lysin is discharged into the zona pellucida where it digests polypeptide chains subjected to a tensile load by the penetrating sperm (Green, 1988). The first mechanism might be expected to be relatively insensitive to the total amount of zona lysin in the acrosome, provided the sperm surface remains adequately coated with enzyme. The second mechanism, however, might be expected to depend on the total amount of zona lysin released, since it relies upon the bulk concentration in the zona pellucida following diffusion of the enzyme into it. The principal candidate for the zona lysin at present is acrosin, activated from proacrosin during the course of the acrosome reaction (Brown et al., 1975a; Meizel \& Mukerji, 1976; Green, 1978b). Despite extensive investigations of the enzyme, the amount available to an individual spermatozoon in the act of penetration has not been measured, although an estimate of the amount has been made from considerations of acrosomal volume (Green, 1988). This paper describes the measurement of the acrosin content of a guinea-pig spermatozoon, and the amount available for release during the acrosome reaction. 


\section{Materials and Methods}

The active-site titrant 3'-(4-guanidinobenzoyloxy)-spiro[isobenzofuran-1(3H),9'-[9H]xanthen]-3-one (3HFGB) was synthesized by the method of Green (1985), 7-N-benzoylargininamido-4-trifluoromethylcoumarin (BATC) from 7-amino-4-trifluoromethylcoumarin in a manner similar to that described by Zimmerman et al. (1977) for 7-Nbenzoylargininamido-4-methylcoumarin (Green, 1986), and $p$-nitrophenyl- $p^{\prime}$-guanidinobenzoate by the method of Chase \& Shaw (1970). 7-Amino-4-trifluoromethylcoumarin for the synthesis of BATC was obtained from Eastman Kodak, Rochester, NY, USA. A23187 and trypsin were obtained from Sigma Chemical Co., St Louis, MO, USA; sodium barbitone and $50 \%$ glutaraldehyde from $\mathrm{BDH}$, Poole, Dorset, UK. All other reagents were reagent grade. Fluorescence assays were performed on an Aminco-Bowman spectrofluorimeter at $22^{\circ} \mathrm{C}$.

Guinea-pig spermatozoa were obtained as described previously (Green, 1978a) and resuspended in $10 \mathrm{ml}$ $\mathrm{Ca}^{2+} /$ Hepes buffer. All subsequent incubations were at $37^{\circ} \mathrm{C}$. Two $0.5 \mathrm{ml}$ samples were removed for zero time-point measurements. Each sample was added to $0.5 \mathrm{ml} 20 \mathrm{mM}-\mathrm{HCl}$ in a Beckman microfuge tube and shaken gently. The final $\mathrm{pH}$ was 2.35 at $22^{\circ} \mathrm{C}$. After $30 \mathrm{sec}$, tubes were centrifuged in a Beckmann microfuge for a further $30 \mathrm{sec}$. The supernatant $(0.9 \mathrm{ml})$ was assayed immediately by addition to $1.8 \mathrm{ml}$ BATC in buffer containing $300 \mathrm{~mm}-\mathrm{Tris}-\mathrm{HCl}$, $\mathrm{pH} 8.0$, and $150 \mathrm{mM}-\mathrm{CaCl}_{2}$. The time course for hydrolysis was established by following the increase in fluorescence (excitation $365 \mathrm{~nm}$, emission $495 \mathrm{~nm}$ ). The acrosome reaction was induced at $37^{\circ} \mathrm{C}$ by addition of $90 \mu \mathrm{A} 23187$ in dimethyl sulphoxide (DMSO) to the remaining $9 \mathrm{ml}$ of sperm suspension (Green, 1978a). Samples of $0.5 \mathrm{ml}$ were removed for each time point, and acid extracted and assayed as before. The time course for dissociation of acrosin-inhibitor complex at $37^{\circ} \mathrm{C}$ was established by incubating a sperm suspension with an equal volume of $20 \mathrm{~mm}-\mathrm{HCl} 30 \mathrm{~min}$ after an acrosome reaction had been induced by A23187. Samples (1 ml) were centrifuged as before, and the supernatant $(0.9 \mathrm{ml})$ assayed for acrosin activity with BATC.

Stoichiometric measurements of acrosin content were made on a sperm suspension which had been incubated for $30 \mathrm{~min}$ with $\mathrm{A} 23187$, treated subsequently with an equal volume of $20 \mathrm{~mm}-\mathrm{HCl}$ and allowed to stand at $37^{\circ} \mathrm{C}$ for a further $30 \mathrm{~min}$. After centrifugation, supernatant $(0.9 \mathrm{ml})$ was added directly to a solution of $3 \mathrm{HFGB}(1.8 \mathrm{ml})$ in $0.1 \mathrm{M}$-sodium barbiturate buffer, $\mathrm{pH} 8 \cdot 3$, containing up to $0 \cdot 2 \mathrm{M}-\mathrm{CaCl}_{2}$. The time course was followed at $22^{\circ} \mathrm{C}$ for $10 \mathrm{~min}$. In some experiments, DMSO up to a final concentration of $0.2 \mathrm{M}$ was incorporated into the buffer. The trypsin used to calibrate the 'burst' characteristics of 3HFGB was itself calibrated colorimetrically with $p$-nitrophenyl- $p$ 'guanidinobenzoate (NPGB) (Chase \& Shaw, 1970).

Sperm counts were measured on a Neubauer cytometer after fixing an aliquant of the original suspension with an equal volume of $2 \%$ glutaraldehyde in $0.15 \mathrm{M}$-sodium cacodylate buffer, $\mathrm{pH} 7.4$. After an initial inspection to determine the number of spermatozoa which had undergone an acrosome reaction (usually $2-3 \%$ ), the fixed sperm suspension was pipetted vigorously to break up rouleaux and then counted.

The volume of the guinea-pig sperm acrosome was estimated from models of a hemi-section of the sperm head made from Plasticine. The shape of the sagittal section was made to conform to published cross-sections (Fawcett, 1965; Green, 1978a).

\section{Results}

Nomarski light microscopy shows that exposure of guinea-pig spermatozoa to $\mathrm{pH} 2.35$ removes the acrosome completely. Brief exposure to these acid conditions also solubilizes the acid-extractable protease activity present in the acrosome (Green, 1978b). The time course for the appearance of the rapidly-extractable protease activity following A23187 treatment of the spermatozoa was followed for periods of up to $1 \mathrm{~h}$. It was essentially complete $10-20 \mathrm{~min}$ after the induction of the acrosome reaction. Thereafter, it remained constant. An additional increment of acid-extractable activity appeared when spermatozoa that were fully activated with A23187 were acid-extracted for longer periods $(30 \mathrm{~min})$. For spermatozoa which had been induced to undergo an acrosome reaction $30 \mathrm{~min}$ before extraction, this increment approximately doubled the protease activity produced initially (Fig. 1). Exposure of this acid extract to $\mathrm{pH} 2.35$ for periods of $1-2 \mathrm{~h}$ resulted in no detectable loss of activity. The emergence of additional proteolytic activity following prolonged acid extraction was relatively slow at room temperature, but occurred more rapidly at $37^{\circ} \mathrm{C}$. A standard procedure of $30 \mathrm{~min}$ for the A23187-induced acrosome reaction, followed by $30 \mathrm{~min}$ for the acid extraction by $20 \mathrm{mM}-\mathrm{HCl}$, both at $37^{\circ} \mathrm{C}$, was adopted for producing maximum protease activity.

The stoichiometric amount of protease activity released by the standard procedure referred to above was measured using the active-site titrant 3HFGB (Green, 1985). This monovalent, fluorogenic titrant is extremely sensitive and will measure absolute amounts of protease in the 10-100 pmol range. Experiments on guinea-pig acrosin to establish the conditions which produced the optimum burst of the fluorescent leaving group, 3-hydroxyfluoran (3HF), both in terms of 


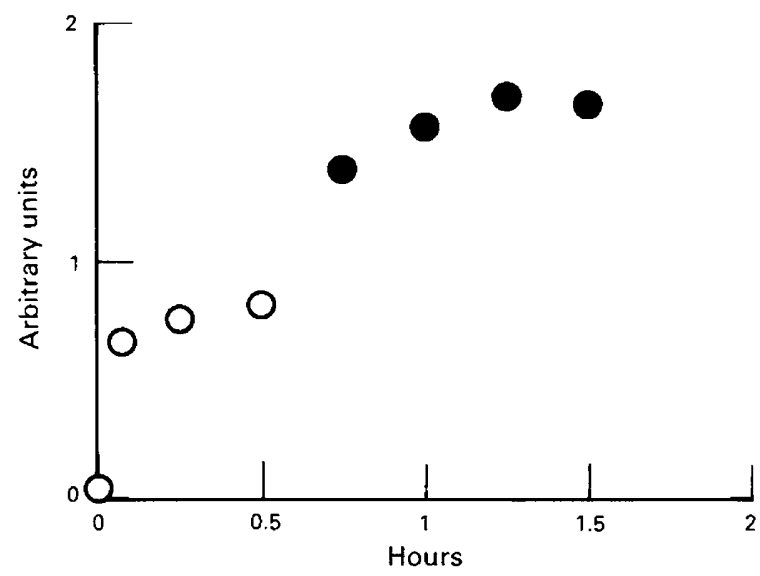

Fig. 1. The time course for the emergence of protease activity in a suspension of guinea-pig spermatozoa induced to undergo the acrosome reaction at $\mathrm{pH} 7.4$ by the ionophore $\mathrm{A} 23187$. Protease activity was measured with the fluorogenic substrate 7-N-benzoylargininamido-4trifluoromethylcoumarin (BATC). Open circles show the initial increase in extractable acrosin activity. At $30 \mathrm{~min}$ the $\mathrm{pH}$ of the suspension was reduced to 2.35 by the addition of an equal volume of $20 \mathrm{~mm}-\mathrm{HCl}$. The emergence of further acrosin activity, attributed to the dissociation of an acrosin inhibitor, is shown by the filled circles.

speed of production and maximum burst size, were modelled closely on those described by Brown et al. (1975b) for ram acrosin. The velocity of the burst reaction increased considerably in the presence of $\mathrm{CaCl}_{2}$ at concentrations up to $0.2 \mathrm{M}$. The reaction of a crude guinea-pig sperm extract in $0.1 \mathrm{M}$-sodium barbiturate buffer containing $0.2 \mathrm{M}-\mathrm{CaCl}_{2}$ is shown in Fig. 2(a). After the initial burst, production of the leaving group, $3 \mathrm{HF}$, proceeded at a steady rate. DMSO was without effect on this response. The burst size was obtained by extrapolation to zero time, and calibrated stoichiometrically with trypsin (Fig. 2b).

Samples from 3 guinea-pigs gave 192, 137 and 212-pmol acrosin/ml respectively for the $10 \mathrm{ml}$ sperm suspensions. The principal difficulty in the measurements lay in the continuing turnover of $3 \mathrm{HFGB}$ after the initial 'burst' of $3 \mathrm{HF}$ production. Sperm counts were $51.6 \times 10^{6}, 44.7 \times 10^{6}$ and $49.5 \times 10^{6} / \mathrm{ml}$ suspension for the 3 animals leading to final estimates of the number of acrosin molecules per sperm of $2.24 \times 10^{6}, 1.84 \times 10^{6}$ and $2.58 \times 10^{6}$. Errors arose principally in the measurement of sperm counts, and the time-zero value of the 'burst' of 3HF. They were estimated to give an approximately $20 \%$ error in the number of acrosin molecules per spermatozoon.

\section{Discussion}

The design and interpretation of the experiments described in this paper rest in large measure on those of Brown et al. (1975a, b) for ram acrosin, and data on the activation of proacrosin from rabbit, hamster and guinea-pig spermatozoa (Mukerji \& Meizel, 1975; Meizel \& Mukerji, 1976; Gaddum-Rosse \& Blandau, 1977; Green, 1978b; Goodpasture et al., 1981; Huang et al., 1985).

The time course for the appearance of acrosin in guinea-pig spermatozoa after induction of the acrosome reaction by $\mathrm{A} 23187$ is shown in Fig. 1. The first part of the curve is taken to reflect the conversion of proacrosin to acrosin during a normal acrosome reaction; the second part to reflect the acid dissociation of the protein acrosin inhibitor to reveal latent acrosin activity. The times obtained for initial activation are similar to those obtained previously for guinea-pig spermatozoa (Green, 1978b; Goodpasture et al., 1981; Huang et al., 1985), but the acid dissociation step, being conducted at $37^{\circ} \mathrm{C}$ in the experiments described here, is more rapidly accomplished. As in the 
(a)

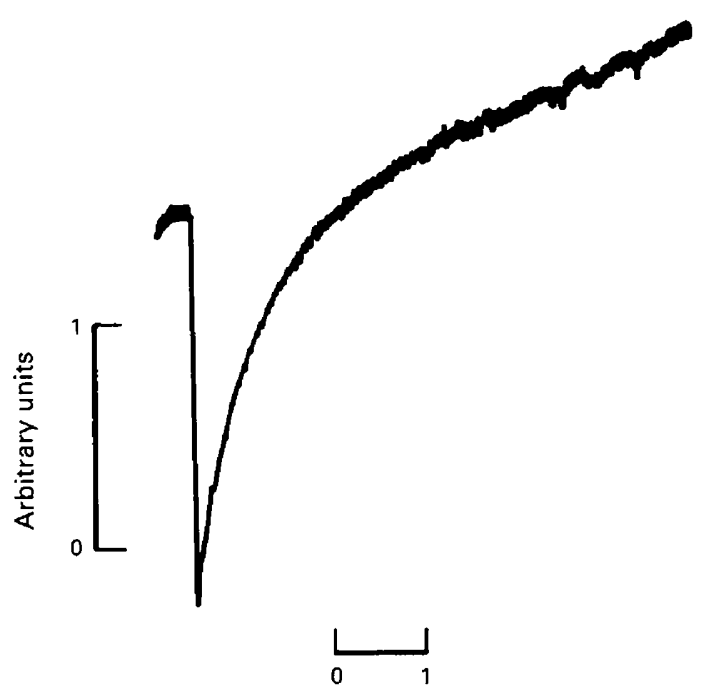

(b)

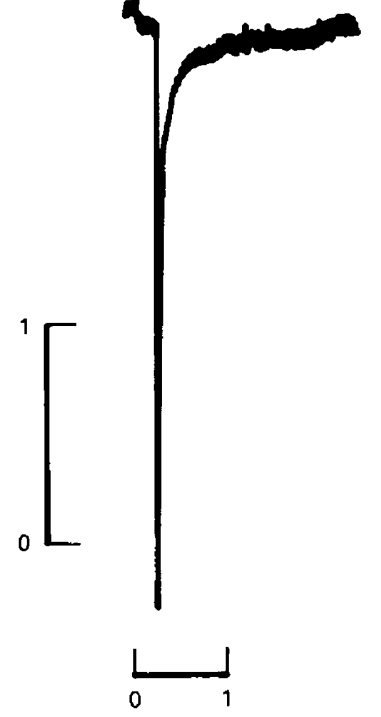

Minutes

Fig. 2. Active-site titration of (a) acrosin and (b) trypsin with the titrant 3 HFGB in a maximally-activated guinea-pig sperm extract. In (a) after the initial burst of $3 \mathrm{HF}$ production, turnover of the titrant continues at a significant rate, indicating the instability of the $p$-guanidinobenzoylated acrosin intermediate. The quantity of acrosin being measured is approximately $70 \mathrm{pmol}$. In (b) the amount of trypsin in this calibration is $\sim 103 \mathrm{pmol}$. The initial response is much faster than in (a) and the burst of $3 \mathrm{HF}$ production, once completed, leads to little additional 3HFGB turnover. This indicates a much higher stability for the p-guanidinobenzoylated trypsin intermediate over its acrosin counterpart.

results of Goodpasture et al. (1981) and Huang et al. (1985), acid dissociation of acrosin inhibitor increased the amount of acrosin activity detected. In the present experiments, approximately half the total acrosin activity is obtained before acid dissociation of the inhibitor. This is comparable, given the errors involved, to the figures given by Goodpasture et al. (1981). However, very little free acrosin appears following the acid extraction in the experiments described by Huang et al. (1985), suggesting that there may be considerable variation in the amount of acrosin inhibitor associated with guinea-pig spermatozoa.

Acrosin activity was quantitated after activation and acid dissociation using a sensitive active-site titrant (Green, 1985). The use of a similar titrant to measure acrosin activity has previously been described for purified ram acrosin (Brown et al., 1975b). The guinea-pig extract shows an initial burst, followed by a significant turnover of the p-guanidinobenzoylated enzyme intermediate. This turnover is a property of the benzoylated enzyme intermediate and not the titrant per se. It can be compared with the response of a similar amount of trypsin (Fig. $2 \mathrm{~b}$ ) in which the p-guanidinobenzoylated-enzyme intermediate is both more stable and its initial formation more rapid. Significant turnover of the enzyme intermediate was also seen with ram acrosin (Brown et al., 1975b), although apparently it could, on occasion, be suppressed by including dimethylsulphoxide in the assay buffer. The addition of dimethylsulphoxide was without effect on the guinea-pig extract.

The estimated potential acrosin content of a guinea-pig spermatozoon, based on the measurements described here, is approximately $2 \times 10^{6}$ molecules, although only half would be available as 'free' acrosin following the acrosome reaction because of the presence of the inhibitor. This may be compared with the value obtained from considerations of acrosomal volume and protein content. 
From measurements of micrographs (Fawcett, 1965; Green, 1978a) and model building, the volume of the guinea-pig acrosome is about $42 \mu \mathrm{m}^{3}$. The fraction of the acrosome occupied by water is likely to be of the order of $65 \%$, leaving $\sim 35 \%$ for protein, etc. (Green, 1988); for a partial specific volume of protein of $0.75 \mathrm{~cm}^{3} / \mathrm{g}$ (Minton, 1980), this gives a protein content of $\sim 20$ pg per acrosome. The measured protein content of the guinea-pig acrosome is about 10 pg protein (Huang et al., 1985). Given the uncertainties involved, and the possibility of significant amounts of carbohydrate on the acrosomal proteins, a 2 -fold difference is not large. However, the weight of protein accounted for by $2 \times 10^{6}$ molecules of proacrosin would, for an $M_{\mathrm{r}}$ of $56000 / 54000$ (Hardy et al., 1987), be about $190 \mathrm{fg}$ per acrosome, thus accounting on a per weight basis for no more than about $1.9 \%$ of the total protein. Even allowing for some uncertainty in the calculations, the amount of acrosin (in the form of proacrosin) present in the acrosome is much less than might have been expected. One possible reason is that the inhibitor recombines with the acrosin during the course of the active site titration, so causing an underestimate of acrosin content. However, this clearly does not happen with ram acrosin (Brown et al., 1975b), and the fact that the turnover of the benzoylated intermediate stabilizes to a steady state increase within $3 \mathrm{~min}$ or so of the reaction being started suggests that it does not happen here. Even if it did, it would only halve the amount of acrosin detected. It may be that the acrosin which is measured is only a fraction of the total proacrosin (because of incomplete activation of proacrosin, premature degradation of acrosin, etc.) or that the titrant 'burst' is, for some reason, substantially sub-maximal.

It is impossible to say what number of molecules would suffice to produce sufficient digestion of the zona pellucida to permit spermatozoa to penetrate if a soluble zona lysin is involved. However, the fact that the zona lysin would need to act over at least the thickness of the zona (i.e. $\sim 10 \mu \mathrm{m}$ ) indicates that considerable dilution of acrosomal contents would occur for a spermatozoon discharging its acrosomal contents at the zona surface. Not only that, but a beating flagellum attached to a support generates a flow field (Lighthill, 1976). Where spermatozoa are penetrating cumulus-free zonae pellucidae, this flow would tend to flush acrosomal contents away from the zona surface, and may also do so where the cumulus is intact. This flow, and the small acrosomes in some species (e.g. mouse, rat, hamster, human), suggest that soluble acrosin may play little part in securing penetration of the zona pellucida by spermatozoa. It may be that a major role for acrosin lies, instead, in freeing the sperm head from the shroud of plasma and acrosomal membranes which remains attached to the zona surface after a zona-induced acrosome reaction. This freeing occurs after the initial attachment of spermatozoa to the zona surface and is a precondition of sperm penetration beginning.

This work was supported by the Medical Research Council of New Zealand.

\section{References}

Austin, C.R. \& Bishop, M.W.H. (1958) Role of the rodent acrosome and perforatorium in fertilization. Proc. R. Soc. B 149, 241-248.

Baltz, J.M., Katz, D.F. \& Cone, R.A. (1988) Mechanics of sperm-egg interaction at the zona pellucida. Biophys. J. 54, 643-654.

Brown, C.R., Andani, Z. \& Hartree, E.F. (1975a) Studies on ram acrosin: isolation from spermatozoa, activation by cations and organic solvents, and influence of cations on its reaction with inhibitors. Biochem. $J$. 149, 133 - I46.

Brown, C.R., Andani, Z. \& Hartree, E.F. (1975b) Studies on ram acrosin: fluorometric titration of operational molarity with 4-methylumbelliferyl p-guanidinobenzoate. Biochem. J. 149, 147-154.

Chase, T., Jr \& Shaw, E. (1970) Titration of trypsin, plasmin, and thrombin with p-nitrophenyl-p'guanidinobenzoate $\mathrm{HCl}$. Methods Enzymol. 19, 20-27.

Drobnis, E.Z., Yudin, A.I., Cherr, G.N. \& Katz, D.F. (1988) Hamster sperm penetration of the zona pellucida: kinematic analysis and mechanical implications. Devl Biol. 130, 311-323.

Fawcett, D.W. (1965) The anatomy of the mammalian spermatozoon with particular reference to the guinea-pig. Z. Zellforsh. mikrosk. Anat. 67, 279-296.

Gaddum-Rosse, P. \& Blandau, R.J. (1977) Proteolytic activity of guinea-pig spermatozoa after induction of the acrosomal reaction in vitro. Am. J. Anat. 149, $423-430$.

Goodpasture, J.C., Reddy, J.M. \& Zanefeld, L.J.D. (1981) Acrosin, proacrosin and acrosin inhibitor of Downloaded from Bioscientifica.com at 04/26/2023 12:19:04PM via free access 
guinea pig spermatozoa capacitated and acrosomereacted in vitro. Biol. Reprod. 25, 44-55.

Green, D.P.L. (1978a) The induction of the acrosome reaction in guinea-pig spermatozoa by the divalent metal cation ionophore A23187. J. Cell Sci. 32, 137-151.

Green, D.P.L. (1978b) The activation of proteolysis in the acrosome reaction of guinea-pig sperm. $J$. Cell Sci. 32, 153-164.

Green, D.P.L. (1985) A fluorogenic active-site titrant for serine proteases. Analyt. Biochem. 147, 487-490.

Green, D.P.L. (1986) Histochemical localization of serine proteases in real time using fluorogenic substrates and image-intensifying video microscopy. Proc. Univ. Otago Med. Sch. 63, 59-60.

Green, D.P.L. (1987) Mammalian sperm cannot penetrate the zona pellucida solely by force. Expl Cell Res. 169, 31-38.

Green, D.P.L. (1988) Sperm thrusts and the problem of penetration. Biol. Rev. 63, 79-105.

Green, D.P.L. \& Purves, R.D. (1984) Mechanical hypothesis of sperm penetration. Biophys. J. 45, $659-662$.

Hardy, D.M., Wild, G.C. \& Tung, K.S.K. (1987) Purification and initial characterization from guinea-pig testes and epididymal spermatozoa. Biol. Reprod. 37, 189-199.
Huang, T.T.F., Jr, Hardy, D., Yanagimachi, H., Teuscher, C., Tung, K., Wild, G. \& Yanagimachi, R. (1985) $\mathrm{pH}$ and protease control of acrosomal content stasis and release during the guinea-pig sperm acrosome reaction. Biol. Reprod. 32, 451-462.

Lighthill, J. (1976) Flagellar hydrodynamics. SIAM Review 18, 161-230.

Meizel, S. \& Mukerji, S.K. (1976) Biochemical studies of proacrosin and acrosin from hamster cauda epididymal spermatozoa. Biol. Reprod. 14, 444 450.

Mukerji, S.K. \& Meizel, S. (1975) The molecular transformation of rabbit testis proacrosin into acrosin Archs Biochem. Biophys. 168, 720-721.

Minton, A.P. (1980) Thermodynamic nonideality and the dependence of partition coefficient upon solute concentration in exclusion chromatography. Application to self-associating and non-self-associating solutes. Application to hemoglobin. Biophys. Chem. 12, 271-277.

Zimmerman, M., Ashe, B., Yurewicz, E.C. \& Patel, G. (1977) Sensitive assays for trypsin, elastase, and chymotrypsin using new fluorogenic substrates. Analyt. Biochem. 78, 47-51. 